\title{
Microstructure and mechanical properties of magnetron sputtered Ti-Si-N coatings with different silicon content
}

\author{
Driss Dergham $^{\text {a, b* }}$, Lounis Chekour ${ }^{\mathrm{a}}$, Adel Khen ${ }^{\mathrm{a}}$ \\ ${ }^{a}$ Laboratory Microstructures and Defects in Materials, Department of physics, University Frères Mentouri \\ Constantine 1, Road of Ain El Bey, Constantine -25000, Algeria. \\ ${ }^{\mathrm{b}}$ Advanced Technology Development Center, Department Ionized Environments City of 20th august 1956 Baba \\ Hassen, 16303, Algiers, Algeria. \\ * Corresponding Author: ddergham1 @gmail.com \\ Received 15 May 2017 Revised manuscript received: 7 Nov $2017 \quad$ Accepted form: 21 Nov 2017
}

\begin{abstract}
This work deals with the deposition and characterization of (Ti-Si-N) coatings. A series of Ti-Si-N thin films with different silicon content were deposited on $\mathrm{Si}$ (100) substrate by RF magnetron sputtering in an $\mathrm{Ar}-\mathrm{N}_{2}$ gas mixture. The influence of Si content on the microstructural and mechanical properties of the as deposited. The as deposited films were studied by using different characterization techniques such as SEM equipped with Energy Dispersive X-ray spectroscopy (EDS) for determining the composition of the films, XRD was used to determine microstructural composition and nano-indentation with MTS XP system for mechanical properties. Scherer's formula was used to determine the grain size, from the full width at half maximum of (111) experimental peaks, residual stresses of the films were measured by an optical interference apparatus using Newton's ring method

Results reveal that the film deposited with $\mathrm{Si}$ content of 20 at. \% has a dense nanostructure and the surface morphology of the Ti-Si-N coatings show neither holes nor column headings. The film deposited with $\mathrm{Si}$ content of 33 at. \% shows a surface morphology of damaged surface. The X-ray spectra show that Ti-Si-N coatings deposited with Si content of 0 at.\%, 27 at.\%, 33 at.\%, 40 at.\% possess a preferential orientation in the direction of (111) and this orientation peak disappears for films with low of Si content. The residual stress built in the coating is compressive and they increase with increase in $\mathrm{Si}$ content and reach a maximum of 2.22 GPa. The hardness of the Ti-Si-N films also increases to a maximum with increase in $\mathrm{Si}$ content beyond which further addition of the Si decrease the hardness. The TiN grain size as calculated from the XRD diffraction peak decreases with increase in the Si content to saturation value of around $12.8 \mathrm{~nm}$ for films without addition of silicon to $3.8 \mathrm{~nm}$ for films with 40 at. \% of $\mathrm{Si}$
\end{abstract}

Keywords: hard coating, magnetron sputtering, residual stress; grain size, Ti-Si-N 


\section{INTRODUCTION}

In the last 30 years, the efforts of many of research has been directed to the deposition of hard coating thin films for industrial applications like machining, wet or dry milling (P. Holubar et al. 2000) and cutting tools (Ning Jiang et al. 2004). Among the thin film materials of interest are $\mathrm{Ti}-\mathrm{N}, \mathrm{Ti}-$ Al-N, Ti-C, Si-C and W-C which are endowed with good mechanical properties (H. Atanabe.2003) and (C. H. Zhang. 2006) et al. Among these materials, Ti-Si-N films have paid a particular interest due to its multiple properties such as mechanical properties, wear resistance, high chemical thermal and stability. In order to improve the mechanical properties of these layers, a lot of studies have been carried out.

Several studies reports that adding Silicon (Si) into Ti-N changes the microstructure and gives a superhard Ti-Si$\mathrm{N}$ films (Niederhofer and 1999) (X.P.Hu 2002) et al. N. Jiang et al reported that the hardness and elastic modulus of their films increased to a maximum values of $35 \mathrm{GPa}$ and 383.2 GPa respectively with increase in Si content to about 9 at.\% followed by a decrease in both the hardness and elastic modulus with further increase in Si content. Z.G. Li et al also reported that the hardness of their film increased significantly to 48 GPa with increase in Si content to 5.8 at.\% and then decreased slightly with further increase in the Si content. (M. Nose et al ). 2003 reported that the hardness of their film increased to $37 \mathrm{GPa}$ with increase in $\mathrm{Si}$ content to around 5 - 8 at.\% followed by a decrease to $22 \mathrm{GPa}$ for the film with 22.5at. $\%$.
In this study, Ti-Si-N thin films have been deposited on Si (100) substrate by reactive RF- magnetron sputtering. The objective of this work is to study the effect of the silicon content in the Ti-N layers on their microstructural and mechanical properties

\section{EXPERIMENTAL TECHNIQUES}

\section{Material Deposition}

Ti-Si-N coatings were deposited on $\mathrm{Si}$ (100) wafers in R.F $(13.56 \mathrm{MHz})$ reactive magnetron sputtering system. The deposition chamber consisted of a cylindrical stainless steel reactor of 230 $\mathrm{mm}$ diameter and $250 \mathrm{~mm}$ height. The sputtering cathode was a thick pure titanium target (purity: 99.99\%and diameter $=76 \mathrm{~mm}$ ) on which square shaped pure silicon pieces of two centimeter edges were fixed, and was continuously water cooled. The number of silicon pieces was varied for different set of films for the purpose of changing the silicon content in the as-deposited films. The substrates were mounted at the center of circular substrate holder (100 $\mathrm{mm}$ in diameter). The distance between the target and the substrate holder was maintained at a distance equal to 50 $\mathrm{mm}$.

Prior to deposition, the samples were chemically degreased and ultrasonically cleaned and mounted on the substrate holder in the sputtering chamber. Before introducing the gases into the chamber in continuous gas flow, the reactor is pumped down and the sputtering 
chamber is evacuated to a pressure below 10-2 Pa. The pressure was maintained by a device which consists of a penning and baratron gauges. Argon of high purity (99.99990\%) was used as the sputtering gas and nitrogen of purity $99.99 \%$ was used as the reactive gas. Bothe Gases, argon and nitrogen were introduced separately, and a gas flow control system was used to control the flow rates of gases. The flow rate of the nitrogen was adjusted in such a way that total amount of nitrogen in deposition chamber is fixed to $20 \%$. The working gas pressure was about $0.2 \mathrm{~Pa}$. The duration of deposition process was fixed at $45 \mathrm{~min}$ for all the films studied in this work. The deposition conditions of Ti-Si-N films used in this work are summarized in Table.1.

Table 1. Deposition conditions for the magnetron sputtered Ti-Si-N Films used in this study.

\begin{tabular}{lc}
\hline Target & $\begin{array}{c}\text { Ti metal + Pieces } \\
\text { of Silicon }\end{array}$ \\
\hline $\begin{array}{l}\text { Target-substrate } \\
\text { distance }\end{array}$ & $50 \mathrm{~mm}$ \\
\hline Base Pressure & $10^{-2} \mathrm{~Pa}$ \\
\hline Sputtering gas & Argon \\
\hline $\begin{array}{l}\text { Reactive } \\
\text { sputtering gas }\end{array}$ & $\begin{array}{l}\text { mixture gases } \\
\text { morking gas }\end{array}$ \\
\hline $\begin{array}{lc}\text { Wressure } \\
\text { Pritrogen in }\end{array}$ \\
\hline Sputtering power & $150 \mathrm{~W}$ \\
\hline Deposition time & $45 \mathrm{~min}$ \\
\hline Bias substrate & $250 \mathrm{~V}$ \\
\hline Substrate temperature & Not heated \\
\hline
\end{tabular}

\section{Material Characterization}

The surface morphology of the films was investigated by using Scanning Electron Microscopy (SEM). This SEM was equipped with an Energy Dispersive Spectroscopy (EDS) used to determine the chemical composition of the as deposited films. The structure and crystallinity of the as-deposited films were investigated by $\mathrm{X}$ ray diffraction (XRD) in a Bragg-Brentano geometry ( $\theta-2 \theta$ geometry), with $\mathrm{Cu} \mathrm{K \alpha}$ radiation $(\mathrm{K} \alpha=1.54 \AA)$.

The structure and crystallinity of the Ti-Si-N films were investigated using $\mathrm{X}$ ray diffraction (XRD) in a Bragg-Brentano geometry $(\theta-2 \theta$ geometry) with $\mathrm{Cu} \mathrm{K} \alpha$ radiation $(\mathrm{K} \alpha=1.54 \AA)$. The scanning range of the $2 \theta$ angle was performed from $30^{\circ}$ to $70^{\circ}$ at room temperature. The average grain size was estimated using Debye-Sherrer equation [9] below:

$$
g(h k l)=\frac{0.9 \lambda}{\beta \cos \theta} \text {. }
$$

Where $\beta$ is the corrected full width at half maximum (FWHM) of a Bragg peak at Bragg angle, $\theta$ and $\lambda$ is X-ray $\mathrm{Cu}(\mathrm{K} \alpha)$ radiation wavelength. The residual stresses of the films were measured by an optical interference apparatus using Newton's ring method, the stress value was calculated from the interference pattern according to the Stoney's equation given below:

$$
\sigma_{r e s}= \pm \frac{E_{s}}{6(1-v)} \times \frac{e_{s}^{2}}{e_{f}}\left(\frac{1}{R}-\frac{1}{R_{0}}\right) \ldots
$$


Where $E_{s}$ is the Young's modulus of substrate, $v$ is the Poisson's coefficient of the substrate, $\mathrm{e}_{\mathrm{s}}$ is the thickness of the substrate, $e_{f}$ is the thickness of the film, $R_{0}$ and $\mathrm{R}$ are the radius of curvature of the substrate before and after deposition respectively. The mechanical properties, i.e., the hardness and the Young modulus of the as-deposited films were determined by means of nanoindentation tests performed on a Nanoindenter XP equipped with a Berkovich diamond tip where a maximum load of $10 \mathrm{mN}$ was used. The diamond Berkovich indenter was forced into the thin films being tested under displacement load with a profile following a linear increase in $2 \mathrm{mN}$ to $10 \mathrm{mN}$ with a holding time of $10 \mathrm{~s}$. The Oliver-Pharr method was used to determine hardness and the Young modulus of the specimens from the unloading curve (Qianhua. Kan et al .2013)

\section{RESULTS AND DISCUSSIONS}

\section{SEM analysis}

Figures 1(a) and (b) show the surface morphology of the Ti-Si-N coatings with $\mathrm{Si}$ content of 20 and 33 at. \% respectively. The coating with Si content of 20 at. \% showed what was believed to be nanocrystalline Si phase embedded within a smooth phase of fine grained or amorphous TiN phase. Neither holes nor columnar heads were observed as reported by other researchers. The Ti-Si-N coating of this film contains dense nanostructures of fine grains of $6.81 \mathrm{~nm}$ in size as calculated by dynamic recrystallization (DRX) technique. These results appeared to be consistent with the work reported by (Diserens et al. 1998)where transformation of columnarstructured Ti-N coating into a dense and fine-grained $\mathrm{Ti}_{1-\mathrm{x}}-\mathrm{Si}_{\mathrm{x}}-\mathrm{N}$ was observed in their coating when 12 at. \% of Si was added using unbalanced magnetron sputtering. Figure 1(b) shows that increase in the $\mathrm{Si}$ content to 33 at. \% produced a similar morphology, however, very fine lines and cracks were present on this Ti-Si-N coating. These features are believed to be defects due to the compressional stress which has been reported to result in small fine fractures (Zong-Jian Liu et al .2008)

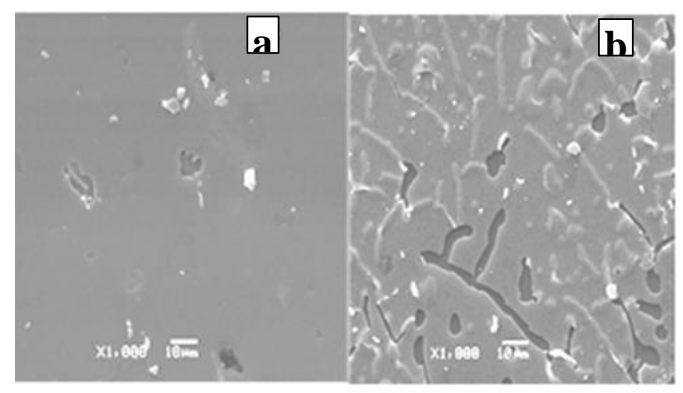

Figure. 1. Surface morphology of Ti-Si-N: (a) 20 at. $\% . S i$, (b) 33 at. $\%$ Si.

\section{X-ray analysis}

Figure 2 shows the XRD pattern of Ti-Si-N thin films with different $\mathrm{Si}$ content. The diffractogrammes show the presence of mixed phases of TiN, TiSi and Si in these films depending on the $\mathrm{Si}$ content incorporated into the TiN coatings. Only a single peak diffraction peak from TiN (111) plane at around $36.6^{\circ}$ is observed in the TiN coating without Si. The film with 20 at. \% $\mathrm{Si}$ showed the appearance of the diffraction peak from the c-Si (111) plane but this peak disappeared when the $\mathrm{Si}$ content was increased to 24 at. \%. This 
peak is believed to be from the sputtered Si pieces on the target which formed isolated phases in the amorphous TiN matrix in the film structure. Increase in Si content of 24 at. \% resulted in the collapse of this c-Si diffraction peak in the structure of this coating as the sputtered $\mathrm{Si}$ pieces gets incorporated into the amorphous TiN matrix forming Ti-Si-N coating. Increase in Si content to 27, 33 and 40 at $\%$ showed the appearance of this c-Si peak again and this diffraction peak increased in intensity due to the increase in $\mathrm{Si}$ content indicating saturation of unsatisfied bonds to incorporate the $\mathrm{Si}$ atoms. The presence of crystalline TiN phase made its appearance with the appearance of the TiN (111) diffraction peak in the film with Si content of 27 at. \%. The film with Si content of 33 at. \% showed the presence of $\mathrm{Ti}$ (111) as well as $\mathrm{TiN}$ (200) diffraction peaks at around $42.6^{\circ}$. These TiN peaks decreased in intensity in the film with Si content of 27 , 33 and 40 at. \%. The broad Ti (111) peak produced by these films suggested the presence of crystalline TiSi phase and this broad peak was due to the overlapping of the TiN (111) and TiSi (102) peaks. The presence of Si resulted in strain in the in the film structure and the existence of strain in the structure of the TiN coatings has been reported to result in the preferred orientation of the TiN plane to be translated into the (111) direction (L. Rebouta et al. 2000). The TiN diffraction peak broadened and its intensity decreased, which indicated a decrease in the size of the Ti-N crystals (Z.T. Yang et al. 2009). The decrease in intensity of the Ti-N (111) peak has been related to the presence of $\mathrm{Si}_{3} \mathrm{~N}_{4}$ phase ( $\mathrm{J}$. Kaminski. 2005), (K. Yamamoto .2003),
(D. Merl. 2004) et al since nanocrystalline Ti-N grains were reported to be interconnected by a thin layer of $\mathrm{Si}_{3} \mathrm{~N}_{4}$ (ncTi-N/a- $\mathrm{Si}_{3} \mathrm{~N}_{4}$ ) (Dayan $\mathrm{Ma}$ et al, 2007). However, in this work, crystalline $\mathrm{Si}_{3} \mathrm{~N}_{4}$ was not observed in the coating with 27 to 40 at. \% Si which clearly showed decrease in intensity of the TiN (111) and (102) peaks. Thus, the $\mathrm{Si}_{3} \mathrm{~N}_{4}$ interconnecting the Ti-N crystalline grains was amorphous and this has been observed by others too (Myung Chang Kang. 2005), (C.K. Chung. 2009), (Z.T. Yang. 2012) et al. There are also reports which are consistent with the results reported in this work which attributed the absence of crystalline $\mathrm{Si}_{3} \mathrm{~N}_{4}$ or Ti-silicide phases to the presence of amorphous $\mathrm{Si}$ phases in the film structure (Z.T. Yang et al. 2009)

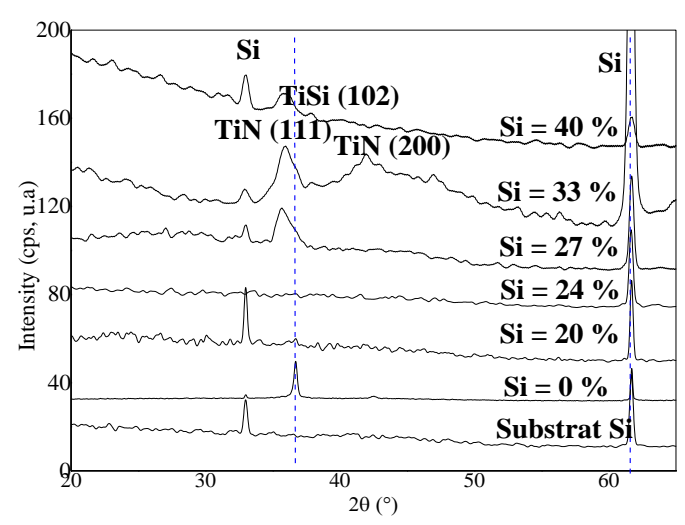

Figure. 2. XRD spectra of Ti-Si-N thin films

\section{Particle size}

The size of the TiN crystalline grains was obtained from the FWHM of TiN (111) diffraction peak using the Scherer's formula. Fig. 3 presents the relationship between the crystalline grain size of $\mathrm{Si}$ and TiN with the $\mathrm{Si}$ content in the film 
structure. The sizes of $\mathrm{Si}$ and $\mathrm{TiN}$ grains decreased with increase in Si content in the film structure. This result is in agreement the results on similar work reported by (L. Rebouta. 2000) where the crystalline grain size decreased from approximately $16 \mathrm{~nm}$ to $4 \mathrm{~nm}$ when the Si content was increased from 7 to19 at \%. (Dayan Ma. 1998) reported a decrease in crystalline grain size of $\mathrm{TiN}$ to a minimum value of $4 \mathrm{~nm}$ with increase in $\mathrm{Si}$ content to approximately 13 at. $\%$.

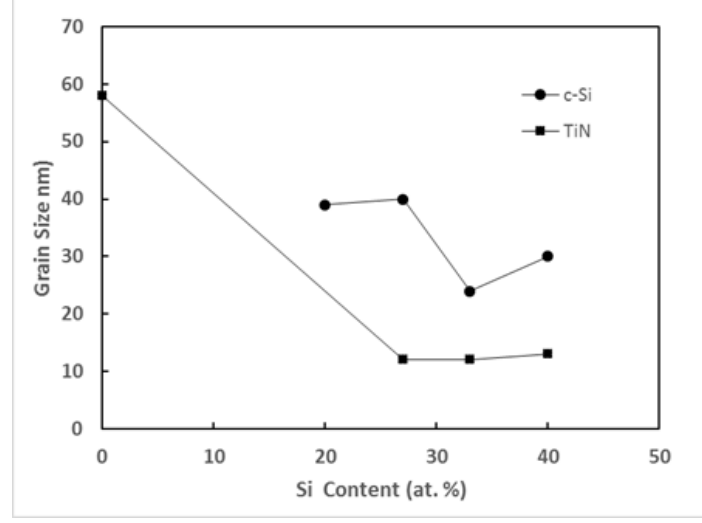

Figure. 3. Evolution of $c$-Si and TiN grain sizes of Ti-Si-N thin films versus $\mathrm{Si}$ content.

\section{Residual stress}

Figure 4 presents the variation of residual stress as a function of $\mathrm{Si}$ content on the films. The Newton rings tests were used to evaluate the residual stress of the Ti-Si-N thin films deposited on the $\mathrm{Si}$ substrate using the Stoney's equation (1). All of the internal stress measured in this work was compressive stress. The residual stress increased from $0.4 \mathrm{GPa}$ for pure Ti-N film to a maximum of $2 \mathrm{GPa}$ for the film with 33 at.\% Si followed by a decrease to 1.6 $\mathrm{GPa}$ for the film with 40 at.\% of Si content. The high crystallinity of the TiN phase in the film with 33 at. \% contributed to the significant increase in residual stress in this film. This result is in agreement with the results reported by (Z. G. Li et al. 2005). The internal stress was caused by the lattice distortion due to the difference between the atomic sizes of $\mathrm{Ti}, \mathrm{Si}$ and $\mathrm{N}$ which have radii $0.147,0.117$ and $0.053 \mathrm{~nm}$, respectively.

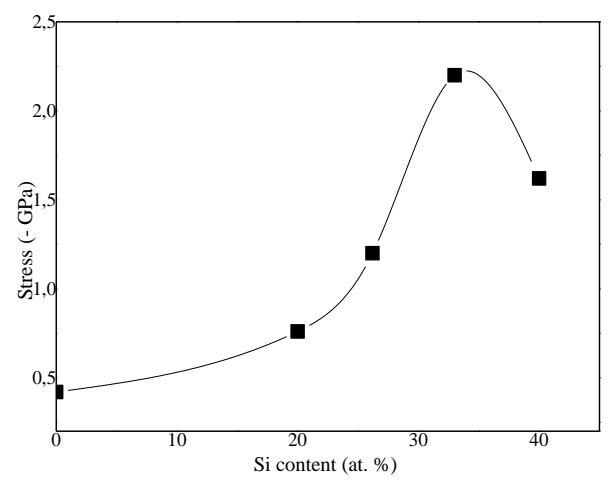

Figure. 4. Residual stress in Ti-Si-N thin films versus Si content.

\section{Mechanical Properties}

Figure 5 shows the relationship between the Ti-Si-N films hardness $(\mathrm{H})$ and Young's Modulus (E) as a function of Si content. It can be seen that hardness and Young's Modulus of the films increase from 11.9 $\mathrm{GPa}$ to $21.73 \mathrm{GPa}$ and 227.6 to $248 \mathrm{GPa}$ respectively for pure Ti-N film and the film with 20 at.\% Si. The hardness then decreased rapidly from 21.7 GPa to $10.1 \mathrm{G}$ $\mathrm{Pa}$ when Si content increased from 20 at. \% to 40 at. \%. The Young's Modulus continued to increase to a maximum of 275.7 $\mathrm{GPa}$ for the film with 33 at.\% of $\mathrm{Si}$ before dropping steeply to $11 \mathrm{GPa}$ for the film with 40 at.\%. The lowest hardness and Young's Modulus recorded by these films were lower than the values recorded for pure TiN coating in this work. The 
behavior of increase in hardness up to an optimal Si content is consistent with results reported by other researchers. In most reports, the hardness of the film reached a much higher maximum at lower optimal $\mathrm{Si}$ content. The increase in the hardness is attributed to the $\mathrm{Si}$ atom incorporated into the coatings resulting in increase in nanocrystalline phase compared to amorphous phase formed in the nano-composite structure (C.K. Chung et al. 2012). Veprek et al. 1998) contributed the increase in hardness of Ti-Si-N films with increase in Si content up to an optimal point followed by a decrease in the grain size. In this work, it was shown that the incorporation of large grain size c-Si into amorphous TiN matrix in the form of isolated nanocrystalline $\mathrm{Si}$ phases in the Ti-Si-N film with $\mathrm{Si}$ content of 20 at. \% contributed by the sputtered c$\mathrm{Si}$ pieces resulted in film with the maximum hardness. (C. Vipin et all. 2010) reported that the hardness and Young's modulus of their films decreased linearly to a minimum of 18.6 and $203.4 \mathrm{GPa}$ respectively. They attributed this behavior to the decrease in the mean free path and porous microstructure as the $\mathrm{Si}$ content increased. The residual compressive stress in this film was less than 1.5 GPa for film with 27 at. \% of Si content and below (see Fig. 4) which is relatively low compared to pure TiN film which has a hardness of around $25 \mathrm{GPa}$ (S. Polaki et al. 2012). This suggested that the nano-crystalline $\mathrm{TiN}$ phase in these films were low compared to the amorphous phases in this film and the film could be porous in structure.

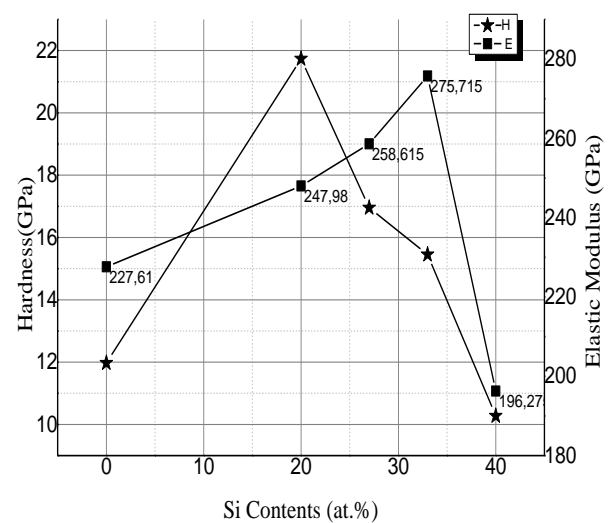

Figure. 5. Hardness and Elastic Modulus of Ti-Si-N films as function of Si content.

\section{The Films Toughness}

Toughness of the films expressed by $\mathrm{H} / \mathrm{E}$ is shown in Figure.6. this parameter is reported by many authors to be a more suitable parameter for predicting wear resistance rather than hardness alone (A. Leyland. and A. Matthews. 2000) The H/E value increased to the highest recorded value of around 0.087 for this work for the film with $\mathrm{Si}$ content of 20 at. $\%$ and decreased continuously with increase in $\mathrm{Si}$ content to 0.052 for the film with 40 at. \% $\mathrm{Si}$. This decrease could be due to the change in the phase composition by the incorporation of the $\mathrm{Si}$ atoms in $\mathrm{TiN}$ structure. The high $\mathrm{H} / \mathrm{E}$ value for coating with 20 at \% Si showed that this coating was the most resistant to wear compared to the other films. This coating recorded a high hardness value but a relatively low elastic modulus which could contribute to reduction in wear (A. Leyland. and A. Matthews. 2000). The incorporation of $\mathrm{Si}$ by RF magnetron sputtering of Si pieces on a single TiN target although simple resulted in film with the highest $\mathrm{H} / \mathrm{E}$ value at higher optimal $\mathrm{Si}$ content with low $\mathrm{H} / \mathrm{E}$ value relative to the high value recorded by 
(Musil. 2012) which was larger than 0.1 for Ti-Si-N coating with a $\mathrm{Si}$ content close to 13 at. $\%$.

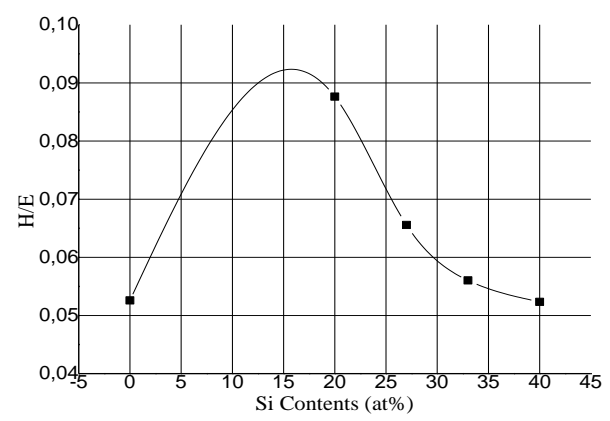

Figure. 6. H/E of Ti-Si-N as a function of Si content,

\section{CONCLUSIONS}

In this work, Ti-Si-N thin films have been deposited by RF Magnetron Sputtering on silicon (100) substrates. The Si content in the films could be easily controlled through changing the number of the $\mathrm{Si}$ pieces on a single TiN target. The silicon content was shown to have an important influence on the microstructure and mechanical properties of films. The TiN crystalline grain size calculated from XRD peaks decreased with increase in Si content. The mechanical properties as recorded from the hardness and elastic modulus reached a maximum value in the Ti-Si-N coating with 20 and 33 at. \% $\mathrm{Si}$ respectively and decreased to hardness and elastic modulus values lower than the pure TiN coating in this work for the film with Si content of 40 at. \%. The incorporation of $\mathrm{Si}$ by $\mathrm{RF}$ magnetron sputtering of $\mathrm{Si}$ pieces on a single TiN target although simple resulted in film with low hardness and wear resistance.

\section{ACKNOWLEDGEMENTS}

We would like to acknowledge Dr. Corinne Nouveau (Arts Métiers-Paris-Tech; LaBoMaP) and Dr N. Saoula (CDTA) Alger for their support in the characterization and the deposition of the thin film coatings of this work respectively.

\section{REFERENCES}

Adrian L., Allan M. (2000). On the significance of the $\mathrm{H} / \mathrm{E}$ ratio in wear control: a nanocomposite coating approach to optimised tribological behavior Wear 246:1-11.

Atanabe H. , Yutaka S., Chaoyin N., Akiro A., Saburo O., Nobuya I.(2003) The mechanical properties and microstructure of $\mathrm{Ti}-\mathrm{Si}-\mathrm{N}$ nanocomposite films by ion plating, Surf. Coat.Technol. 169-170:452455.

Bushroa. A R., Rahbari. R. G, Masjuki H.H.,Muhamad. M.R.(2012). Approximation of crystallite size and microstrain via XRD line broadening analysis in TiSiN thin films Vacuum 86:1107-1112.

Chang Kang M., Suk Kim J., Kim Kwang Ho. (2005) Cutting performance using high reliable device of $\mathrm{Ti}-\mathrm{Si}-\mathrm{N}$-coated cutting tool for high-speed interrupted machining, Surface \& Coatings Technology 200 :1939-1944.

Chung C K., Chang H C., Chang S C.,Liao M W., Lai C C.(2012) Evolution of enhanced crystallinity and mechanical property of 
nanocomposite $\mathrm{Ti}-\mathrm{Si}-\mathrm{N}$ thin films using magnetron reactive cosputtering Journal of Alloys and Compounds 537:318-322

Dayan D Ma., Shengli Ma., Wang Y., Qikun X., Kewei Xu.(2007) Study on properties and microstructure of $\mathrm{Ti}-\mathrm{Si}-\mathrm{N}$ coatings deposited in deep holes Surface \& Coatings Technology 201: 4901-4904.

Diserens M., Patscheider J., Lévy F.(1998), Improving the properties of titanium nitride by incorporation of silicon, Surf. Coat. Technol. 108109:241-246.

Holubar P., Jilek M., Sima M.(2000) Present and possible future applications of superhard nanocomposite coatings, Surf. Coat. Technol. 133/134:145-151

$\mathrm{Hu}$ X P., Li G Y., Gu M Y.(2002) Microstructure and properties of $\mathrm{Ti}-$ $\mathrm{Si}-\mathrm{N}$ nanocomposite films., J.Vac.Sci and Technol.(A), Vacuum. Surf. And Films 20 (6):1921-1926.

Jiang N., Shen Y G., Mai Y W., Chan T Simon C T.(2004) Nanocomposite $\mathrm{Ti}-\mathrm{Si}-\mathrm{N}$ films deposited by reactive unbalanced magnetron sputtering at room temperature, Materials Science and Engineering B106: 163-171.

Kaminski J., Rudnicki J., Nouveau C.,Savan .A., Beer P.(2005) Surface and Coatings Technology. Resistance to electrochemical corrosion of CrxNy- and DLCcoated steel tools in the environment of wet wood.200: 8386.

Kan Q., Wenyi Y, Guozheng $\mathrm{K}$ and Qingping S. (2013) Oliver-Pharr indentation method in determining elastic moduli of shape memory alloys - a phase transformable material, Journal of Mechanics 61: 2015-2033.

Li Z G., Mori M., Miyake S., Kumagai M., Saito H., Muramatsu Y. (2005) Structure and properties of $\mathrm{Ti}-\mathrm{Si}-\mathrm{N}$ films prepared by ICP assisted magnetron sputtering, Surface \& Coatings Technology 193:345-349.

Merl D K., Panjan P., Cekada M., Macek M.(2004) The corrosion behavior of $\mathrm{Cr}-(\mathrm{C}, \mathrm{N})$ PVD hard coatings deposited on various substrates Electrochimica Acta 49:1527-1533.

Musil J. (2012) Hard nanocomposite coatings: Thermal stability, oxidation resistance and toughness Surf. Coat. Technol. 207 :50-65

Niederhofer A., Nesladek P., Mannling HD., Moto K., Veprek S., Jilek M.(1999) Structural properties, internal stress and thermal stability of nc-TiN/a-Si3N4, ncTiN/TiSix and ncTil-yAlySix)N superhard nanocomposite coatings reaching the hardness of diamond, Surf. Coat.Technol. 120 - 121 :173178.

Nose M., Deguchi Y., Mae T., Honbo E., Nagae T., Nogi K.(2003) Influence of sputtering conditions on the structure and properties of $\mathrm{Ti}-\mathrm{Si}-\mathrm{N}$ thin films prepared by r.f.reactive sputtering, Surface and Coatings Technology 174 175:261-265.

Polaki S., Ramaseshan R., Jose F., Dash S., and Tyagi A K. (2012). Evolution of Structural and Mechanical Properties of TiN Films on SS 304LN .10:1-6

Rebouta L., Tavares C J., Aimo R.,Wang Z., Pischow K., Alves E., Rojas T 
C., Odriozola J A. (2000) Hard nanocomposite $\mathrm{Ti}-\mathrm{Si}-\mathrm{N}$ coatings prepared by $\mathrm{DC}$ reactive magnetron sputtering, Surface and Coatings Technology 133-134, 234-239.

Veprek S., Nesladek P., Niederhofer A.,Gglatz F., Sima Jilek.(1998) Recent progress in the superhard nanocrystalline composites: towards their industrialization and understanding of the origin of the superhardness, Surf. Coat. Technol. 108/109: 138-147.

Vipin Chawla V., Jayaganthan R.,Chandra R.(2010) Influen ofSputtering Pressure on the Structure and Mechanical Properties of Nanocomposite Ti-Si-N Thin Films, J. Mater. Sci. Technol., 26: 673678.

Yamamoto K., Sato T., Takahara K., Hanaguri K.(2003) Properties of Ti,Cr,Al)N coatings with high $\mathrm{Al}$ content deposited by new plasma enhanced arc-cathode Surface and Coatings Technology, 174-175: 620-626.

Yang Z T., Yang B., Guo L P., Fu D J.(2009) Synthesis of Ti-Si-N nanocomposite coatings by a novel cathodic arc assisted middlefrequency magnetron sputtering, Applied Surface Science 255:47204724.

Yang Z T., Yang B., Guo L P., Fu D J.(2009) Effect of bias voltage on the structure and hardness of TiSiN composite coatings synthesized by cathodic arc assisted middlefrequency magnetron sputtering, Journal of Alloys and Compounds 473:437-441.

Zhang C H., Lu X C., Wang H., Luo J B., Shen Y G., Li K Y.(2006) Microstructure, mechanical properties, and oxidation resistance of nanocomposite $\mathrm{Ti}-\mathrm{Si}-\mathrm{N}$ coatings. Appl.Surf.Sci. 252:61416153

Zong Jian L., Ning J., Shen Y G., Xiaonian L. (2008) Stress-induced surface damages in Ti-Si-N films grown by magnetron sputtering, Thin Solid Films 516 :7609- 7614 